\title{
Correction to: Healthy Minds in the Twentieth Century
}

\author{
Steven J. Taylor and Alice Brumby
}

Correction to:

S. J. Taylor and A. Brumby (eds.), Healthy Minds in the Twentieth Century, Mental Health in Historical Perspective, https://doi.org/10.1007/978-3-030-27275-3

In the original version of the book, the following belated corrections have been made:

In chapter 3 note 5 , the misspelled author name "Hedi Rimke" has been corrected to "Heidi Rimke".

In chapter 8 , title has been revised from "Challenging Psychiatric Classification: Healthy Autistic Diversity the Neurodiversity Movement" to "Challenging Psychiatric Classification: Healthy Autistic Diversity and the Neurodiversity Movement".

The corrected book has been updated with these changes.

The updated versions of these chapters can be found at https://doi.org/10.1007/978-3-030-27275-3_3 https://doi.org/10.1007/978-3-030-27275-3_8

(C) The Author(s) 2020

S. J. Taylor and A. Brumby (eds.), Healthy Minds in the Twentieth Century, Mental Health in Historical Perspective, https://doi.org/10.1007/978-3-030-27275-3_12 